\title{
Cathodoluminescence from Nanoscale Scintillators using an Electron Probe Microanalyzer
}

\author{
Carlin D. Ashford ${ }^{1}$, Tajah C. Trapier ${ }^{2}$, Gibin George ${ }^{1}$, Jason Davis ${ }^{3}$, Daryush Ila $^{1}$, and Zhiping Luo ${ }^{1}$ \\ 1. Department of Chemistry and Physics, Fayetteville State University, Fayetteville, NC 28301, USA \\ 2. Cumberland International Early College High School, Fayetteville, NC 28301, USA \\ 3. Oak Ridge Institute for Science and Education, Oak Ridge Associated Universities, Oak Ridge, TN \\ 37830, USA
}

A scintillator can convert high-energy radiations to visible lights, enabling real-time detection and imaging of the radiations. So far, research on scintillators on the nanometer scale is limited [1-3]. In an electron microscope, cathodoluminescence (CL) spectroscopy can be used to study the scintillation since it can provide the luminescence from a small specimen region using a defined beam of high-energy electrons. In this work, we synthesized scintillator nanofibers for studying their CL properties using an electron probe microanalyzer (EPMA).

Polymer solutions were prepared by dissolving 2.0 g polyvinylpyrrolidone (PVP) (molecular weight $\sim 1,200,000 \mathrm{~g} / \mathrm{mol}$ ) in a mixture of $\mathrm{N}, \mathrm{N}$-dimethylformamide (DMF) with ethanol. Ammonium metatungstate were added to the polymer solution with barium chloride $\left(\mathrm{BaCl}_{2}\right)$ or lead chloride $\left(\mathrm{PbCl}_{2}\right)$, respectively, in 1:1 molar ration. The electrospinning was conducted at room temperature with applied voltage of $\sim 18 \mathrm{kV}$. The prepared nanofibers were subsequently calcined at $700{ }^{\circ} \mathrm{C}$ in air for $5 \mathrm{~h}$ to obtain oxide nanofibers. Samples were coated with carbon and analyzed in a JEOL field-emission JXA-8530F EPMA, which was equipped with X-ray energy-dispersive spectrometer (EDS) and wavelengthdispersive spectrometers (WDSs), and xCLent IV Hyperspectral CL System, worked at $20 \mathrm{kV}$.

Fig. 1(a) shows an image of $\mathrm{BaWO}_{4}$ nanofibers after calcination. It is found that the nanofibers are composed of nanoparticles after the calcination, as shown in the magnified image in Fig. 1(b). The EDS analysis, as shown in Fig. 1(c), reveals its composition as almost stoichiometric $\mathrm{BaWO}_{4}$. Nanofibers of $\mathrm{PbWO}_{4}$ were also prepared by the electrospinning method, and the EDS spectrum is shown in Fig. 1(d) with a stoichiometric composition of $\mathrm{PbWO}_{4}$.

The CL spectra of the $\mathrm{BaWO}_{4}$ and $\mathrm{PbWO}_{4}$ nanoscintillators are shown in Fig. 2(a) and (b), respectively. In both spectra, similar broad emission bands appear approximately in the range of $380 \mathrm{~nm}$ to $600 \mathrm{~nm}$. These peaks are the integral intensity of yellow, green and blue bands with the maximum intensity peak in blue region. These $\mathrm{CL}$ bands originate from $\mathrm{O}^{2-}-\mathrm{O}^{-}$oxygen complexes [4]. The $\mathrm{O}^{2-}-\mathrm{O}^{-}$oxygen complexes are associated with the vacancies, which in turn can lead to structural disorders and therefore distorted geometry and orientation of coordination polyhedrons. These structural disorders favor the emission from the samples [5]. It is also worthwhile to mention that during the sample synthesis, PbO can volatilize easily than $\mathrm{WO}_{3}[5]$ to create $\left(\mathrm{WO}_{3}+\mathrm{F}\right)$ centers, where $\mathrm{F}$ is an electron bound to a negative ion vacancy [6] in $\mathrm{PbWO}_{4}$, generating the CL emissions [6, 7].

\section{References}

[1] Z. Luo, J.G. Moch, S.S. Johnson, and C.C. Chen. Current Nanosci. 13, 364-372 (2017).

[2] C.Y. Chen, C.W. Hun, S.-F. Chen, C.C. Chen, J.S. Lin, S.S. Johnson, N. Noel, N. Juliely, Z. Luo. Rev. Nanosci. Nanotechnol. 4, 26-49 (2015).

[3] C.C. Chen, S.F. Chang, Z. Luo. Mater. Lett. 112, 190-193 (2013). 
[4] V.A. Kozlov, S.A. Kutovoi, N.V. Pestovskii, A.A. Petrov, S.Y. Savinov, Y.D. Zavartsev, M.V. Zavertyaev, A.I. Zagumenniy. arXiv:1608.06565 [physics.optics] (2016).

[5] D. Zhou, C. Yonghu, S. Chaoshu, et al. Prog. Cryst. Growth Charact. Mater. 40, 173-176 (2000).

[6] M. Anicete-Santos, P.C. Francini, A.N. Cláudio, et al. J. Phys. Chem. C 115, 12180-86 (2011).

[7] The authors acknowledge funding from the NSF HRD 1436120, and Oak Ridge Associated Universities (ORAU) FY 2017 ORAU-Directed Research and Development Grant, coordinated by Mrs. Cathy Fore at ORAU. The instrumentation at FSU was supported by DoD W911NF-09-1-0011, W911NF-14-1-0060, W911NF-15-1-0566 and NSF MRI Program DMR 1626376. C.D. Ashford is a RISE scholar at FSU funded by NIH.
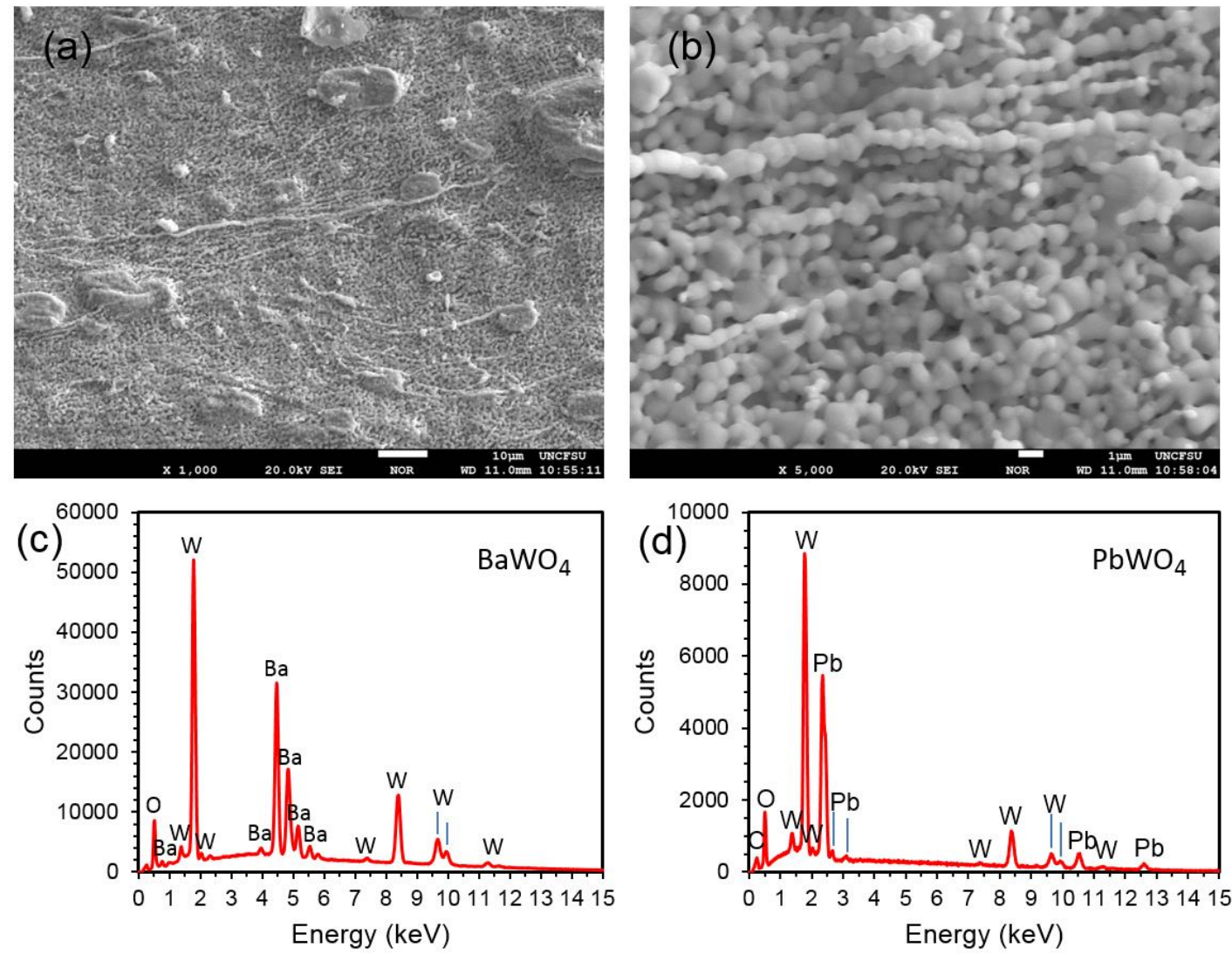

Figure 1. (a, b) Images of $\mathrm{BaWO}_{4}$ nanofibers; (c, d) EDS spectra from $\mathrm{BaWO}_{4}$ and $\mathrm{PbWO}_{4}$, respectively.
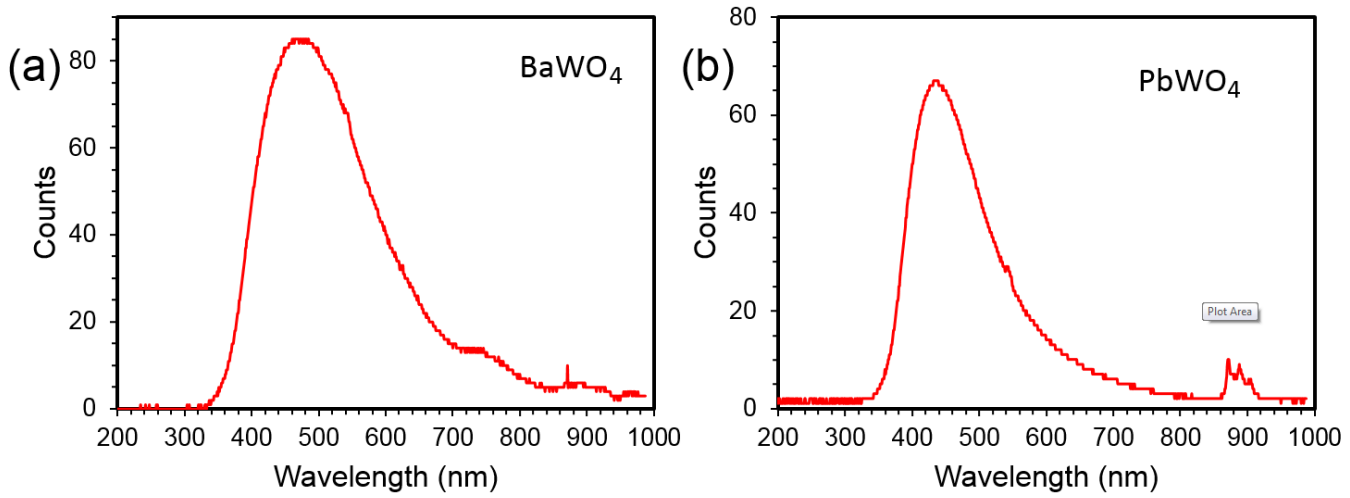

Figure 2. CL spectra from $\mathrm{BaWO}_{4}$ (a) and $\mathrm{PbWO}_{4}$ (b), respectively. 